\title{
Evaluating the Acoustic Properties of Estabragh (Milkweed)/Hollow- Polyester Nonwovens vfor Automotive Applications
}

\author{
Hasani $\mathbf{H}^{*}$, Zarrebini M, Zare M and Hassanzadeh S \\ Department of Textile Engineering, Isfahan University of Technology, Isfahan, 84156-83111, Iran
}

\begin{abstract}
Reduction in noise pollution in general and particularly in automotive industry has become an important issue that has gained the interest of numerous researchers. The present research is aimed to introduce a new product which could serve as an alternative for other commonly used sound absorbing materials. It is expected that hollow fibers due to their structure can significantly influence noise insulation performance of materials in which these fibers are incorporated. Therefore sound absorbing material compose of blend of natural hollow fibers Milkweed or as it known Estabragh and hollow polyester fibers were used to produce needle-punched nonwoven samples. Eighteen different samples were produced by varying blend ratio, mass per unit area, punching density, and frequency of the incident sound. Noise Absorption Coefficient (NAC) of the samples was evaluated using impedance test method. The evaluation procedures were designed using Taguchi method. Results showed samples solely comprise of Estabragh fibers have attained the ability to absorb noise. It was observed that NAC decreases as the amount of Estabragh in the blend is reduced. Although the results showed an increase in punching density improves NAC of the samples, however statistical analysis dismissed the effectiveness of this parameter on sound absorption characteristics of the samples. It was found that NAC increases in direct relation to increase in mass per unit area $\left(\mathrm{g} / \mathrm{m}^{2}\right)$ of the samples. This was attributed to the increase in tortuosity of the samples and the energy losses due to frictional resistance. Finally it was observed that NAC peaks at frequency of $4000 \mathrm{~Hz}$.
\end{abstract}

Keywords: Acoustic; Polyester; Estabragh (Milkweed); Hollow fibers; Noise absorption; Nonwovens; Punching density

\section{Introduction}

Undesirable noise is potentially hazardous and create major health problem in different areas of applications as workshops, residential/ office buildings and transportation. Given the health and safety codes governing the level of noise in these varied locations, the importance of acoustically acceptable environments can be vividly realized. Thus much attention is given to the methods of noise control in association with the considered particular environment of application. In confined spaces such as car cabinet existence of such quiet space that can exclude engine and road noise is of paramount importance which has become a major quality factor [1-3]. The challenge of noise reduction has traditionally focused on using high-weight sound absorbing material with higher damping effect which is undesirable as far as fuel consumption performance of the modern vehicles is concerned. More recent approach in field of automotive noise reduction concerns with application of sound dissipation by the sound absorbing material rather than sound absorption or sound transmission phenomenon. This meets requirements of high-efficiency low-weight materials that do not lead to unnecessary increase in the weight of the vehicle; these materials are classified as porous fibrous material [3-5].

Among the variety of fibrous porous materials, nonwoven structures due to their technical and economical merits are used extensively in numerous automotive applications [6-8]. Nonwovens are generally known as manufactured fibrous sheets, webs or bats of directionally or randomly orientated fibers, both staple and filament, bonded by friction, cohesion or adhesion mechanisms [9]. Acoustic properties of these fibrous porous structures essentially are related to both geometry of component fibers and their arrangement within the structure [7]. The wide variety of fibers, either natural or man-made can be used in nonwovens manufacturing processes. Among them, natural or polymeric hollow fibers due to their unique structures are expected to have superior noise absorption performance. Estabragh is one of these natural indigenous hollow fibers which their physical and mechanical properties were firstly studied by Haghighatkish [10].

Gharehaghaji [11] studied the Carding behavior of Estabragh nonwovens and investigated the damages caused to the fibers using SEM images. Hassanzadeh [12] have also investigated the acoustical performance of Estabragh hollow fibers blended with polypropylene fibers in forms of needle punched nonwovens. They concluded that increasing the Estabragh fibers content in blend significantly leads to increase nonwovens sound absorbency.

Numerous researches on designing the light-weight nonwovens as suitable sound absorbing materials for automotive applications are also available. Mahmoud [4] investigated the effect of hollow fibers component on acoustical performance of nonwoven structures. It was found that more sound was absorbed when the percentage of hollow fibers in the blend increased. It should be stated that using natural fiber nonwoven presents ecological benefit such as saving energy in the production process which is very important for industries.

In this work, the acoustic properties of lightly needled nonwoven fabrics produced from Estabragh/hollow-polyester fibers blends have been investigated. Different variables including blend ratio, needle punching density and fabric mass per unit area $\left(\mathrm{g} / \mathrm{m}^{2}\right)$ have been

*Corresponding author: Hasani $\mathrm{H}$, Department of Textile Engineering, Isfahan University of Technology, Isfahan, 84156-83111, Iran, Tel: +98-0-311-3913; E-mail: h_hasani@cc.iut.ac.ir

Received February 25, 2014; Accepted March 11, 2014; Published March 15 2014

Citation: Hasani H, Zarrebini M, Zare M, Hassanzadeh S (2014) Evaluating the Acoustic Properties of Estabragh (Milkweed)/Hollow-Polyester Nonwovens for Automotive Applications. J Textile Sci Eng 4: 157. doi:10.4172/2165-8064.1000157

Copyright: $\odot 2014$ Hasani $\mathrm{H}$, et al. This is an open-access article distributed under the terms of the Creative Commons Attribution License, which permits unrestricted use, distribution, and reproduction in any medium, provided the original author and source are credited. 
Citation: Hasani H, Zarrebini M, Zare M, Hassanzadeh S (2014) Evaluating the Acoustic Properties of Estabragh (Milkweed)/Hollow-Polyester Nonwovens for Automotive Applications. J Textile Sci Eng 4: 157. doi:10.4172/2165-8064.1000157

Page 2 of 6

considered though the experiments. Using Taguchi statistical design method, the mixture of variables with their specified variation levels was provided.

\section{Experimental}

In this research, comparing the acoustical performance of Estabragh natural hollow fibers with that of the Hollow-polyester manmade fibers has been under consideration. Estabragh fibers used in this investigation were collected from the southern regions of Iran. Table 1 shows specifications of both polyester and Estabragh hollow fibers.

Design points of experiments were set up using Taguchi experimental design method $[13,14]$. The general steps involved in this method are:

- Defining the process objective, or more specifically, a target value for measuring the process response based on the loss function concepts;

- Selecting the design parameters affecting the process objective and specifying the number of variation levels for them;

- Determining the proper orthogonal array according to the number of selected parameters and their variation levels;

- Performing the trials and collecting data of the process response affected by the combination of parameters as indicated in Taguchi orthogonal array table;

- Analyzing data and determining the effect of the different parameters on the process response.

In this work noise absorption coefficient or NAC which was expected to have maximum value was defined as process target. The selected controllable variables affecting NAC were considered as blend ratio, $\left(\mathrm{g} / \mathrm{m}^{2}\right)$, punching density and the frequency of incident sound waves. Different variation levels were allocated to the variable parameters individually in which the parameter blend ratio was given six levels while for the other two, three different variables were selected. Taguchi orthogonal array L18 as indicated in Table 2 was determined in terms of selected number of parameters and their variation levels. Also the details of variation levels for each controllable parameter are given in Table 3.

Eighteen different fibrous webs containing $100 \%, 80 \%, 60 \%, 40 \%$, $20 \%$ of Estabragh and $100 \%$ hollow polyester fibers in three different mass per unit area $\left(\mathrm{g} / \mathrm{m}^{2}\right)$ were prepared using a laboratory-scale carding machine. In order to prevent damage to Estabragh fibers, blending was carried out manually. The carding operation was carried out at steady atmospheric condition of $60-70 \%$ relative humidity, and $20-25^{\circ} \mathrm{C}$ ambient temperature. The carded fibrous webs were needled on a laboratory-scale needling machine equipped with Groz-Beckert 15_18_32_3 felting needles. Needling imparted to the nonwoven layers was adjusted so that three different punch densities including 20.3, 25.4 and 30.5 were provided. A typical SEM image of fibers arrangement within the nonwoven layer is depicted in Figure 1. Some of the specification of lightly needled nonwoven samples is given in Table 4 .

\begin{tabular}{|l|c|c|c|}
\hline \multirow{2}{*}{ Fiber } & \multicolumn{3}{|c|}{ Specifications } \\
\cline { 2 - 4 } & $\begin{array}{c}\text { Length } \\
(\mathrm{mm})\end{array}$ & $\begin{array}{c}\text { Diameter } \\
(\mathrm{mm})\end{array}$ & $\begin{array}{c}\text { Fineness } \\
\text { (Denier) }\end{array}$ \\
\hline Hollow-polyester & 57.14 & 34.4 & 8.62 \\
\hline Estabragh & 34.23 & 25.31 & 3.38 \\
\hline
\end{tabular}

Table 1: Fibers specification.

\begin{tabular}{|c|c|c|c|c|}
\hline \multirow[t]{2}{*}{ Sample No. } & \multicolumn{4}{|c|}{ Variables } \\
\hline & Blend ratio & $(g / m 2)$ & $\begin{array}{l}\text { Punching } \\
\text { density }\end{array}$ & Frequency \\
\hline 1 & 1 & 1 & 1 & 1 \\
\hline 2 & 1 & 2 & 2 & 2 \\
\hline 3 & 1 & 3 & 3 & 3 \\
\hline 4 & 2 & 1 & 1 & 2 \\
\hline 5 & 2 & 2 & 2 & 3 \\
\hline 6 & 2 & 3 & 3 & 1 \\
\hline 7 & 3 & 1 & 2 & 1 \\
\hline 8 & 3 & 2 & 3 & 2 \\
\hline 9 & 3 & 3 & 1 & 3 \\
\hline 10 & 4 & 1 & 3 & 3 \\
\hline 11 & 4 & 2 & 1 & 1 \\
\hline 12 & 4 & 3 & 2 & 2 \\
\hline 13 & 5 & 1 & 2 & 3 \\
\hline 14 & 5 & 2 & 3 & 1 \\
\hline 15 & 5 & 3 & 1 & 2 \\
\hline 16 & 6 & 1 & 3 & 2 \\
\hline 17 & 6 & 2 & 1 & 3 \\
\hline 18 & 6 & 3 & 2 & 1 \\
\hline
\end{tabular}

\begin{tabular}{|l|l|l|l|l|l|l|}
\hline \multirow{2}{*}{ Parameters } & \multicolumn{5}{|c|}{ Variation level } & \\
\cline { 2 - 7 } & Level 1 & Level 2 & Level 3 & Level 4 & Level 5 & Level 6 \\
\hline $\begin{array}{l}\text { Blend ratio } \\
(\% \text { Es }\end{array}$ & 100 & 80 & 60 & 40 & 20 & 0 \\
\hline $\mathrm{g} / \mathrm{m}^{2}$ & 40 & 80 & 120 & - & - & - \\
\hline $\mathrm{p} / \mathrm{cm}^{2}$ & 20.3 & 25.4 & 30.5 & - & - & - \\
\hline $\begin{array}{l}\text { Frequency } \\
(\mathrm{Hz})\end{array}$ & 500 & 2500 & 4000 & - & - & - \\
\hline
\end{tabular}

${ }^{*}$ Es=Estabragh fibers

Table 3: Parameters variation level.

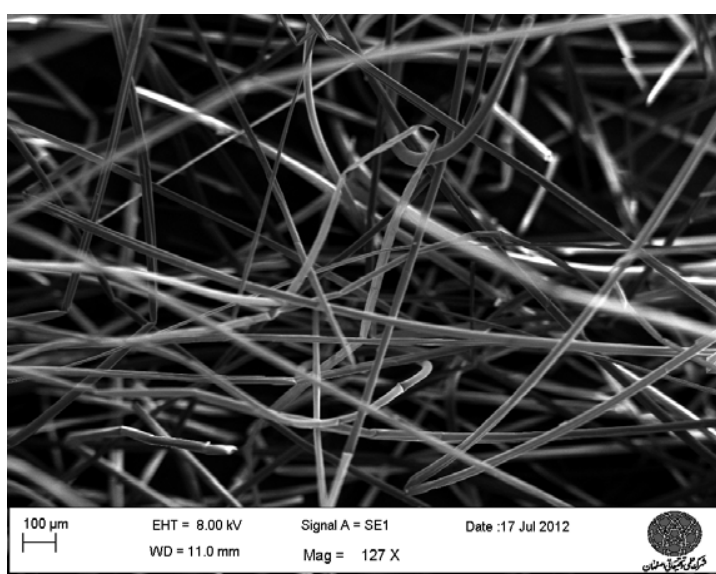

Figure 1: SEM image of nonwoven layer.

In order to evaluate the acoustic performance of Estabragh/hollowpolyester needled nonwovens, Impedance Tube Method was used. The principle of this method is based on ASTM E-1050 or C-348 (Normal Incidence Sound Absorption). This technique is relatively inexpensive and entails the use of a small test sample. As it is depicted in Figure 2, the equipment comprise of a $100 \mathrm{~cm}$ long smooth steel stainless tube, signal generator, microphone and a speaker. Microphone is located on movable platform which can be moved along tube when searching for minimum and maximum value of sound pressure. If " $\mathrm{A}$ " is the intensity 
Citation: Hasani H, Zarrebini M, Zare M, Hassanzadeh S (2014) Evaluating the Acoustic Properties of Estabragh (Milkweed)/Hollow-Polyester Nonwovens for Automotive Applications. J Textile Sci Eng 4: 157. doi:10.4172/2165-8064.1000157

Page 3 of 6

\begin{tabular}{|c|c|c|c|}
\hline \multirow{2}{*}{$\begin{array}{c}\text { Sample } \\
\text { No. }\end{array}$} & \multicolumn{3}{|c|}{ Variables } \\
\hline & Weight & Thickness & Porosity \\
\hline & $\left(g / m^{2}\right)$ & $(\mathrm{mm})$ & $(\%)$ \\
\hline 1 & $56.0_{(\mathrm{CV} \%=11.3)}$ & $1.4_{(\mathrm{CV} \%=4.3)}$ & 97.8 \\
\hline 2 & $70.7_{(\mathrm{CV} \%=13.1)}$ & $1.8_{(\mathrm{CV} \%=8.2)}$ & 97.8 \\
\hline 3 & $87.0_{(\mathrm{CV} \%=10.2)}$ & $2.7_{(\mathrm{CV} \%=3.5)}$ & 98.2 \\
\hline 4 & $75.2_{(\mathrm{CV} \%=8.7)}$ & $1.8_{(\mathrm{CV} \%=12.1)}$ & 97.2 \\
\hline 5 & $99.0_{(\mathrm{CV} \%=6.9)}$ & $3.5_{(\mathrm{CV} \%=0.9)}$ & 97.4 \\
\hline 6 & $195_{(\mathrm{CV} \%=6.8)}$ & $3.9_{(\mathrm{CV} \%=2.3)}$ & 97.2 \\
\hline 7 & $59.2_{(\mathrm{CV} \%=8.8)}$ & $1.2_{\text {(CV\%=7.8) }}$ & 95.5 \\
\hline 8 & $115.2_{(\mathrm{CV} \%=7.5)}$ & $3.8_{(\mathrm{CV} \%=2.7)}$ & 96.2 \\
\hline 9 & $224.0_{(\mathrm{CV} \%=4.6)}$ & $4.1_{(\mathrm{CV} \%=2.5)}$ & 95 \\
\hline 10 & $68.0_{(\mathrm{CV} \%=4.8)}$ & $1.1_{(\mathrm{CV} \%=11.4)}$ & 94.8 \\
\hline 11 & $154.7_{(\mathrm{CV} \%=4.0)}$ & $3.1_{(\mathrm{CV} \%=6.6)}$ & 95.8 \\
\hline 12 & $219.0_{(\mathrm{CV} \%=7.5)}$ & $4_{(\mathrm{CV} \%=6.2)}$ & 95.4 \\
\hline 13 & $89.6_{(\mathrm{CV} \%=6.0)}$ & $1.4_{(\mathrm{CV} \%=10.4)}$ & 95 \\
\hline 14 & $151.2_{(\mathrm{CV} \%=9.0)}$ & $2.1_{(\mathrm{CV} \%=1.1)}$ & 94.3 \\
\hline 15 & $270.4_{(\mathrm{CV} \%=3.1)}$ & $4.1_{(\mathrm{CV} \%=2.9)}$ & 94.8 \\
\hline 16 & $94.0_{(\mathrm{CV} \%=11.2)}$ & $2.1_{(\mathrm{CV} \%=7.4)}$ & 93.7 \\
\hline 17 & $180.0_{(\mathrm{CV} \%=4.8)}$ & $3.2_{\text {(CV\% } \%=1.9)}$ & 95.9 \\
\hline 18 & $252.0_{(\mathrm{CV} \%=3.2)}$ & $3.6_{(\mathrm{CV} \%=5.0)}$ & 95 \\
\hline
\end{tabular}

Table 4: Nonwoven samples specifications.

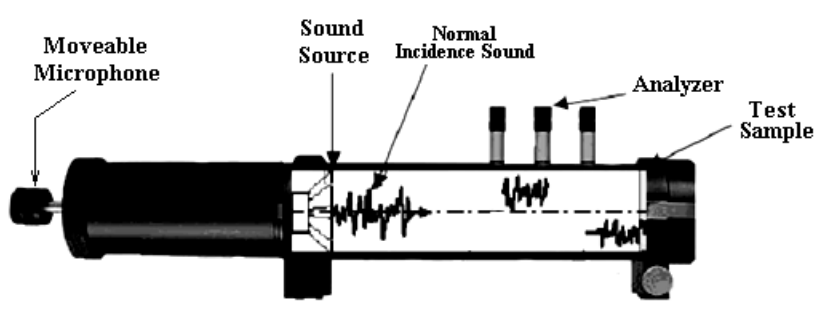

Figure 2: Impedance Tube equipped with one moveable microphone.

of sound waves generated by the source and " $\mathrm{B}$ " is the intensity of reflected sound waves, the ratio $\mathrm{n}$ as a measure of noise absorption is calculated from equation 1 ;

$$
n=\frac{(A+B)}{A-B}=\frac{V_{\max }}{V_{\min }}
$$

Where $V_{\max }$ and $V_{\min }$ are the maximum and minimum voltage detected via digital voltmeter used in the setup. After determining the " $n$ " value, noise absorption coefficients of samples could be calculated according to the following equation:

$$
\alpha=\frac{4}{\left[n+\left(\frac{1}{n}\right)+2\right]}
$$

\section{Results and Discussion}

\section{Taguchi analysis}

In order to evaluate the acoustic performance of the lightly needled nonwovens samples, the noise absorption coefficient measurement based on ASTM-E 1050-1982 was repeated three times for each sample. The calculated NAC values of the samples are listed in Table 5 .

In order to evaluate the effects of controllable parameters on NAC of the samples, Minitab-14 software was employed. In this statistical analysis software, the signal to noise $(\mathrm{S} / \mathrm{N})$ ratio is recognized as analytical basis. $\mathrm{S} / \mathrm{N}$ ratio compares the level of a desired signal to the level of background noise. This ratio indicates the amount of noise in the output of a specified process [15]. By considering the type of response parameters, three general standard $\mathrm{S} / \mathrm{N}$ equations for classification of the objective function including 'larger the better', 'smaller the better', or 'nominal the best' are available. Since the NAC as the process response is expected to have larger values, the loss function of the larger-thebetter quality characteristics was determined that can be described as equations 3 and 4 ;

$$
\begin{aligned}
& L_{j}=\left(\frac{1}{n} \sum_{k=1}^{n} \frac{1}{y_{i}^{2}}\right) \\
& n_{j}=-10 \log L_{j}
\end{aligned}
$$

Where $n$ is the number of tests, $y_{i}$, is the experimental value of the $i_{\text {th }}$ quality characteristic, $L_{j}$ is the overall loss function, and $\eta_{j}$ is the amount of $\mathrm{S} / \mathrm{N}$ ratio. Table 5 shows the $\mathrm{S} / \mathrm{N}$ ratios results in association with all four controllable parameters and their variation levels. Difference between the highest and the lowest $\mathrm{S} / \mathrm{N}$ ratios of each parameter called Delta, is considered as an index which can indicates the effect of the particular parameter on noise absorbency of the samples. According to the Table 6, it can be stated that the Estabragh proportion of the blend with a delta value of 6.66 has the strongest effect on NAC. In order to verify the extent of effectiveness of the controllable parameters on noise absorbency of the samples, variation analysis technique as shown in Table 7 was used. It can be seen that apart from frequency, all other controllable parameters significantly affect the NAC values.

The variation curves of NAC in different levels of controllable parameters are separately depicted in Figure 3. The results indicate that noise absorbency of samples increases as the proportion of Estabragh in the blend increases. Additionally acoustic performance enhances when punching density and/or mass per unit area are increased. From the statistically analysis results it is obvious that the increasing trend in NAC of the samples in terms of sound frequency is not significant.

\section{Effect of proportion of Estabragh in the blend}

SEM images of cross-sections fibers used in the work are shown in Figure 4. According to this image, the ratio of air space to the whole

\begin{tabular}{|l|l|l|l|l|}
\hline \multirow{2}{*}{ Sample No. } & \multicolumn{4}{|c|}{ NAC values } \\
\cline { 2 - 5 } & $R^{*}$ & $R$ 2 & $R 3$ & Mean value \\
\hline 1 & 0.579 & 0.584 & 0.585 & 0.582 \\
\hline 2 & 0.765 & 0.752 & 0.755 & 0.757 \\
\hline 3 & 0.985 & 0.982 & 1 & 0.989 \\
\hline 4 & 0.474 & 0.466 & 0.453 & 0.464 \\
\hline 5 & 0.672 & 0.677 & 0.675 & 0.675 \\
\hline 6 & 0.76 & 0.785 & 0.829 & 0.791 \\
\hline 7 & 0.471 & 0.437 & 0.44 & 0.449 \\
\hline 8 & 0.573 & 0.585 & 0.576 & 0.578 \\
\hline 9 & 0.668 & 0.683 & 0.658 & 0.67 \\
\hline 10 & 0.401 & 0.452 & 0.447 & 0.433 \\
\hline 11 & 0.467 & 0.457 & 0.444 & 0.456 \\
\hline 12 & 0.51 & 0.504 & 0.506 & 0.507 \\
\hline 13 & 0.355 & 0.349 & 0.357 & 0.354 \\
\hline 14 & 0.387 & 0.382 & 0.407 & 0.392 \\
\hline 15 & 0.405 & 0.403 & 0.401 & 0.403 \\
\hline 16 & 0.333 & 0.339 & 0.333 & 0.335 \\
\hline 17 & 0.35 & 0.338 & 0.336 & 0.341 \\
\hline 18 & 0.386 & 0.38 & 0.384 & 0.383 \\
\hline
\end{tabular}

${ }^{*} \mathrm{R}=$ Replication

Table 5: NAC results. 
Citation: Hasani H, Zarrebini M, Zare M, Hassanzadeh S (2014) Evaluating the Acoustic Properties of Estabragh (Milkweed)/Hollow-Polyester Nonwovens for Automotive Applications. J Textile Sci Eng 4: 157. doi:10.4172/2165-8064.1000157

NAC

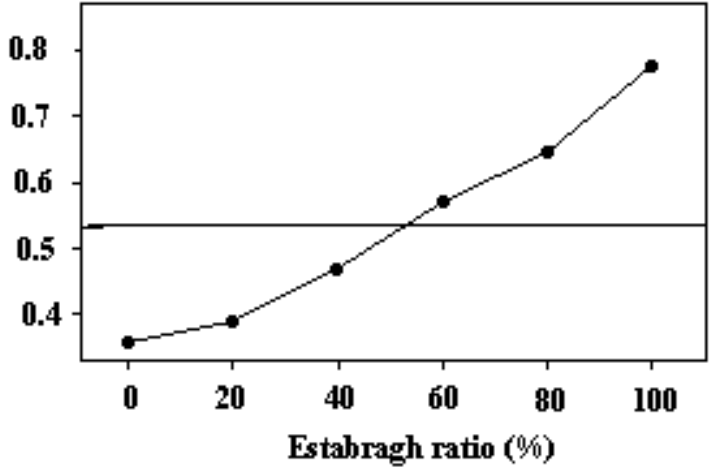

NAC

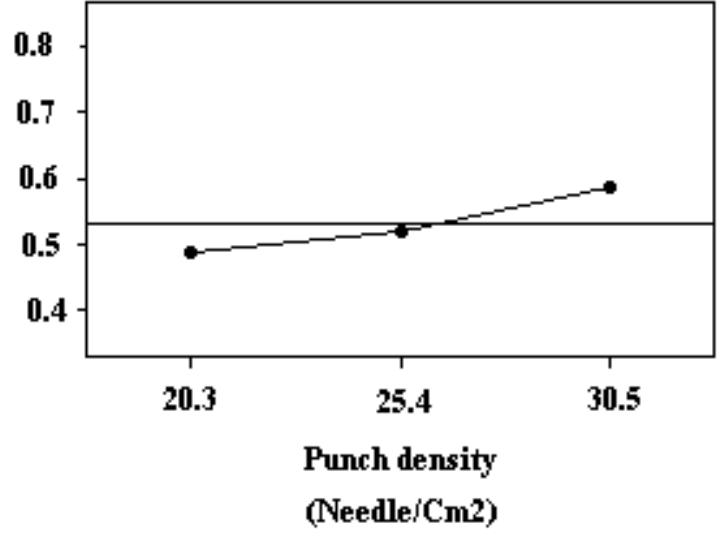

NAC

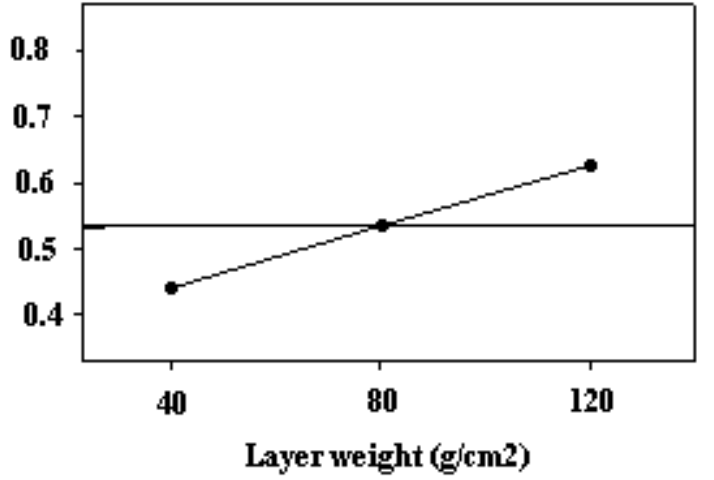

NAC

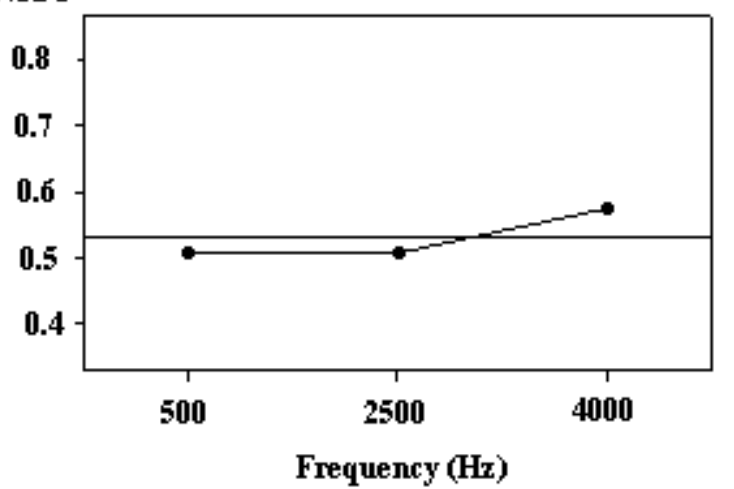

Figure 3: NAC interactions with controllable parameters.

\begin{tabular}{|c|c|c|c|c|c|c|c|c|}
\hline \multirow[t]{2}{*}{ Parameters } & \multicolumn{6}{|c|}{ Variation level } & \multirow{2}{*}{ Delta } & \multirow[t]{2}{*}{ Rank } \\
\hline & Level 1 & Level 2 & Level 3 & Level 4 & Level 5 & Level 6 & & \\
\hline $\begin{array}{l}\text { Blend ratio } \\
\left(\% E s^{*}\right)\end{array}$ & -9.06 & -8.36 & -6.68 & -5.07 & -4.04 & -2.4 & 6.66 & 1 \\
\hline $\begin{array}{l}\text { Layer weight } \\
\left(\mathrm{g} / \mathrm{m}^{2}\right)\end{array}$ & -7.36 & -5.82 & -4.63 & - & - & - & 2.73 & 2 \\
\hline $\begin{array}{l}\text { Punch density } \\
\text { (needle } / \mathrm{cm}^{2} \text { ) }\end{array}$ & -6.48 & -6.01 & -5.31 & - & - & - & 1.17 & 3 \\
\hline Frequency $(\mathrm{Hz})$ & -6.17 & -6.19 & -5.45 & - & - & - & 0.72 & 4 \\
\hline
\end{tabular}

*Es=Estabragh fibers

Table 6: Response for S/N ratios (larger the better).

\begin{tabular}{|c|c|c|c|c|c|}
\hline \multirow[t]{2}{*}{ source } & \multicolumn{5}{|c|}{ Statistical analysis } \\
\hline & DF & Seq. SS & Adj. MS & $F$ & P \\
\hline Blend ratio & 5 & 98.89 & 19.78 & 71.53 & 0 \\
\hline $\begin{array}{l}\text { Layer } \\
\text { weight }\end{array}$ & 2 & 22.52 & 11.26 & 40.72 & 0 \\
\hline $\begin{array}{l}\text { Punch } \\
\text { density }\end{array}$ & 2 & 4.2 & 2.1 & 7.59 & 0.02 \\
\hline Frequency & 2 & 2.15 & 1.08 & 3.9 & $0.08^{*}$ \\
\hline $\begin{array}{l}\text { Residual } \\
\text { error }\end{array}$ & 6 & 1.66 & 0.28 & - & - \\
\hline Total & 17 & 129.41 & - & - & - \\
\hline
\end{tabular}

*The $P$-value $>0.05$ is not significant.

Table 7: Analysis of variance for $\mathrm{S} / \mathrm{N}$ ratios.

fiber volume could be calculated as about 0.25 for hollow polyester fibers while this ratio for Estabragh fibers is approximately 0.80 which is considerably higher $[16,17]$. For this reason, it can be derived that the porosity and the size of the hollow channel of Estabragh fibers is much higher than the hollow-polyester. Therefore, an increment in Estabragh proportion of the blend leads to more frictional losses and greater absorption of sound.

Upon impact of sound waves with porous materials, the transmitted component of the incident sound wave encounters both air and fibers. At the boundaries formed by air and fibers within the material, a single sound wave while travelling through the material structure, branch out into many transmitted and reflected waves which eventually resulted in sound wave energy reduction. Thus an increase in the number of boundaries is bound to enhance sound absorption ability of the fibrous textile material $[1,17]$.

Fiber structural characteristic such as cross-section shape is considered as another factor which could affect the sound absorption behavior of nonwovens by changing in the surface area. Larger fiber surface area influences the boundaries faced by the transmitted sound waves which in turn leads to enhancement of sound absorption ability of the material. Narang [17] have pointed to increase in friction between fibers and air and its effect on improvement in sound absorption. Additionally hollow fibers due to entrapment of air in their central axis which effectively increase the boundaries within the fibrous assembly are expected to induce a two fold increase in the sound absorbency of the fibrous material in comparison to identical fibrous material compose of solid fibers [1]. 


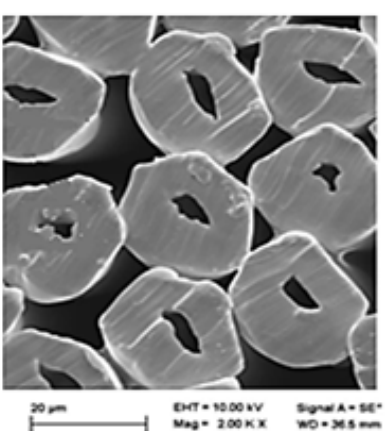

(A)

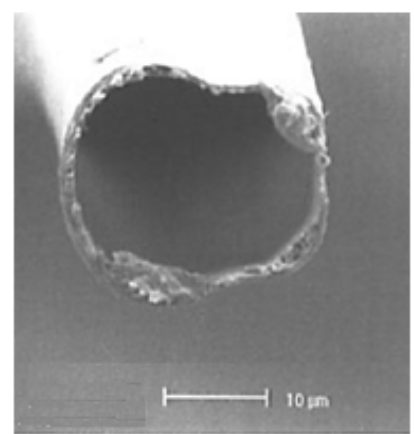

(B)
Figure 4: Fibers SEM images (A) hollow-polyester (B) Estabragh

Previous research [1] has pointed to the importance of fiber diameter on sound insulation property of materials. SEM images and measurement of fiber diameter confirm that Estabragh fibers are finer than hollow-polyester. Assuming a constant value of sample mass per unit area, nonwovens comprised of finer fibers would significantly have a higher number of fibers within their structures than samples made using coarser fibers. This is bound to increase air/fiber boundaries which lead to greater sound absorbency. This explains the superior sound insulation performance of the sample compose of higher proportion of Estabragh fibers.

\section{Effect of mass per unit area}

As it is obvious, the number of fibers within the nonwoven layers structure would be increased as the mass per unit area of layers increases. This in turn, leads to the higher numbers of pores created between the constitutive fibers which eventually results in higher frictional resistance to transmitted sound waves. Not only because of the frictional resistance, but also due to the thickness increment and tortuosity path formation within the nonwoven samples, the sound wave energy losses would be resulted $[18,19]$.Therefore, the reduction of sound wave amplitude which is known as sound absorbency would be happened by the sample.

\section{Effect of punching density}

Increasing the amount of punching density imparted to nonwoven, would increases the fiber entanglement within the nonwoven samples. This in turn results in formation of numerous but smaller pores between the fibers which subsequently increase the sound/fiber interface areas within the fabric structure. Because of this interface changes occurred between fibers and sound waves, the frictional resistance pattern encounter by sound waves and thus more energy would be lost [17]. Although, sever needling leads to excessive breakage of Estabragh fibers, but statistical analysis revealed that increasing the amount of needling applied to the Estabragh/hollow polyester nonwoven samples would significantly improve their noise absorption ability.

\section{Effect of frequency of incident sound}

The frequency in which the sound waves can be absorbed is essentially dependent on the density of materials. Seddeq [1] reported that in dense fabric structures, noise absorption occurs almost at high frequencies while in open structured fabrics, the absorbency would occur at frequencies with relatively low intensity. Results of the present work indicate that higher noise absorption is achieved as sound frequency increases. However this is not confirmed by statistical analysis which point to insignificant effect of this parameter on NAC values.

\section{Conclusion}

In this study, evaluating the effect of Estabragh fibers component in lightly needled nonwoven samples was aimed. Four different controllable parameters including Estabragh fiber ratio in blend, layer weight, punch density and the frequency of sound were selected and the effects of each parameter on noise absorbency were investigated. The results from Taguchi analysis indicated that the Estabragh fibers presence in nonwoven structures improves the acoustic performance of samples. The ratio of whole diameter to fiber diameter of Estabragh fibers is much higher than that of the hollow-polyester fibers. In this case, the higher Estabragh fibers ratio in blend, would increase the surface area of nonwoven As a result, the more frictional losses of sound energy occurred in such nonwoven samples would be resulted to the higher NAC values. The findings also showed that the layer weight has significant effect on nonwovens acoustic performance. Increasing the layer weight leads to increases the number of fibers within the structure which in turn results in more sound energy losses. So, the NAC values increase by increasing the layer weight. Additionally, increasing the density of nonwovens via applying higher punch densities resulted in more noise absorbency. Although the better noise absorption properties achieved by increasing the frequency, but the statistical analysis revealed that the differences are not significant.

\section{References}

1. Seddeq HS (2009) Factors Influencing Acoustic Performance of Sound Absorptive Materials. Aus J Basic Appl Sci 3: 4610-4617.

2. Watanabe K, Minemura Y, Nemoto K, Sugawara H (1999) Development of highperformance all-polyester sound-absorbing materials. JSAE Rev 20: 357-362.

3. Youneung L, Changwhan J (2003) Sound Absorption Properties of Recycled Polyester Fibrous Assembly Absorbers. AUTEX Res J 3: 78-84.

4. Abdelfattah A, Mahmoud GE, Ibrahim, Eman RM (2011) Using Nonwoven Hollow Fibers to Improve Cars Interior Acoustic Properties. Life Sci J 8: 344351.

5. Soltani P, Zarrebini M (2012) The Analysis of Acoustical Characteristics and Sound Absorption Coefficient of Woven Fabrics. Text Res J 82: 875-882.

6. Vasile S, Langenhove LV (2004) Automotive Industry A High Potential Market for Nonwovens Sound Insulation. JTATM 3: 1-5.

7. Tascan M (2005) Acoustical Properties of Nonwoven Fiber Network Structures, Ph.D. Thesis. Textile, Fiber \& polymer Science, Clemson University, USA.

8. Shoshani Y, Yakubov $Y$ (1999) A model for calculating the noise absorption capacity of nonwoven fiber webs. Text Res J 69: 519-526.

9. Castagnede B, Aknine A, Brouard B, Tarnow V (2000) Effects of compression on the sound absorption of fibrous materials. Appl Acoust 61: 173-182.

10. Haghighatkish M, Sheikhzadeh NS (1998) Structure and Properties of a Natural Cellulosic Hallow Fiber. Internat J Engg 11: 101-108.

11. Gharehaghaji AA, Hayat DS (2008) Mechanical Damage to Estabragh Fibers in the Production of Thermobonded Layers. J Appl Polymer Sci 109: 3062-3069.

12. Hassanzadeh S, Hasani H, Zarrebini M (2014) Analysis and Prediction of Noise Reduction Coefficient of Lightly-needled Estabragh/Polypropylene Nonwovens Using Simplex Lattice Design. J Text Inst 105: 256-263.

13. Stone RA, Veevers A (2005) The Taguchi influence on designed experiments J Chemometrics 8: 103-110.

14. Bolboacă SD, Lorentz J (2007) Design of Experiments: Useful Orthogonal Arrays for Number of Experiments from 4 to 16. Entropy 9: 198-232. 
Citation: Hasani H, Zarrebini M, Zare M, Hassanzadeh S (2014) Evaluating the Acoustic Properties of Estabragh (Milkweed)/Hollow-Polyester Nonwovens for Automotive Applications. J Textile Sci Eng 4: 157. doi:10.4172/2165-8064.1000157

Page 6 of 6

15. Joseph VR, Wu CFJ (2002) Performance measures in Dynamic Parameter Design. J Japanese Quality Engg Soc 10: 82-86.

16. Khoddami A, Carr CM, Gong RH (2009) Effect of hollow polyester fibers on mechanical properties of knitted wool/polyester fabrics. Fibers Polymers 10: 452-460.

17. Narang PP (1995) Material parameter selection in polyester fiber insulation for sound transmission and absorption. Appl Acoust 45: 335-358.
18. Koizumi T, Tsujiuchi N, Adachi A (2002) The Development of Sound Absorbing Materials Using Natural Bamboo Fibers, High Performance Structure And Composites Book, WIT Press, UK.

19. Knapen E, Lanoye R, Vermeir G, Van GD (2003) Sound Absorption By PolymerModified Porous Cement Mortars. $6^{\text {th }}$ International Conference on Materials Science and Restoration, Karlsruhe, Germany. 